\title{
Uma proposta metodológica para o ensino dos conceitos de pressão \\ e diferença de pressão
}

\author{
Wilmo Ernesto Francisco Junior \\ Professor de Química da rede pública e privada em Araraquara-SP e \\ Mestrando em Educação na \\ Universidade Federal de São Carlos, Departamento de Metodologia de Ensino, \\ e-mail: wilmojr@bol.com.br
}

*Endereço para correspondência com o autor:

Departamento de Bioquímica e Tecnologia Química, Instituto de Química, Universidade Estadual Paulista, Rua Professor Francisco Degni s/ nº, Caixa Postal: 355, CEP: 14801970, Araraquara-SP, fone: (16)33228657, Fax: (16)33227932 


\title{
Resumo:
}

O presente trabalho objetivou desenvolver, aplicar e avaliar uma proposta metodológica para o ensino qualitativo dos conceitos de pressão e diferença de pressão. Foram desenvolvidas duas atividades experimentais complementares, as quais foram debatidas em sala de aula com ênfase na produção escrita dos alunos. $\mathrm{O}$ estudo foi realizado numa escola pública da cidade de Araraquara-SP, sendo a coleta de dados efetuada por meio de observações e anotações dos estudantes. Os resultados, analisados à luz da teoria piagetiana da equilibração, mostraram que a estratégia desenvolvida foi motivadora e capaz de desencadear perturbações e auxiliar o desenvolvimento do processo de assimilação dos conceitos tratados. Além disso, os registros escritos demonstraram grande potencialidade para se perceber o nível de entendimento dos alunos.

Palavras Chave: diferença de pressão, experimentação, Piaget.

\section{A methodological proposal to the teaching of pressure and pressure difference concepts}

\begin{abstract}
:
The purpose of the present paper was to develop, apply and evaluating a qualitative model of teaching to the concepts of pressure and pressure difference. It was performed two experimental activities, one complementary to another, which were discussed in the classroom with emphasis on the texts written by students. This study was conducted in a public high school from Araraquara-SP. The results were obtained from observations and notes of the students about the phenomenous observed. The findings, analized by Piaget's epistemology, showed that model teaching collaborated with the pupils' interesting and to the development of pertubations which helped a conceptual evolution of the concepts. Besides, the texts written by students demonstrated a great importance to evaluating the students' understanding.
\end{abstract}

Keywords: pressure difference, experimentation, Piaget. 


\section{INTRODUÇÃO}

As ciências químicas e físicas possuem, por si só, um elevado nível de abstração pelo qual se torna bastante complexo transitar. A transição do nível macroscópico ao nível microscópico requer, antes de tudo, que o aluno tenha desenvolvido certos esquemas cognitivos. Conhecimentos obtidos por intermédio de constatações empíricas podem facilitar essa transição.

Segundo Piaget (1964), a aprendizagem é decorrente das contínuas interações entre o sujeito, aquele que irá conhecer, e o objeto, aquilo será conhecido. Todo o conhecimento se origina na ação e tal conhecimento só é possível quando sujeito e objeto relacionam-se de modo que o sujeito age sobre o objeto. Para tanto, o sujeito deve ser impulsionado em direção ao objeto, como se houvesse um desequilíbrio entre eles e, conseqüentemente, o sujeito tende a superar o desnível em que se encontra, devido a uma necessidade.

Toda ação - isto é, todo movimento, pensamento ou sentimento corresponde a uma necessidade. A criança, como o adulto, só executa alguma ação exterior ou mesmo inteiramente interior quando impulsionado por um motivo e este se traduz sempre sob a forma de uma necessidade (uma necessidade elementar ou um interesse, uma pergunta, etc) (Piaget, 1964, p. 14).

Essa necessidade, motivação ou impulso é que incentivará a ação do aprendiz:

A ação é desequilibrada pelas transformações que aparecem no mundo, exterior ou interior, e cada nova conduta vai funcionar não só para restabelecer o equilíbrio, como também para tender a um equilíbrio mais estável que o do estágio anterior a esta perturbação. A ação humana consiste neste movimento contínuo e perpétuo de reajustamento ou de equilibração. É por isso que, nas fases de construção inicial, se pode considerar as estruturas mentais sucessivas que produzem o desenvolvimento como formas de equilíbrio, onde cada uma constitui um progresso sobre as precedentes (Piaget, 1964, p. 14-15). 
A relação sujeito-objeto representa um esforço adaptativo para superar o desnível existente entre um e outro. Superado o desnível chega-se ao estado de equilíbrio entre sujeito e objeto. Nesse processo, denominado de equilibração, duas etapas complementares e, por vezes, simultâneas são destacadas por Piaget: a assimilação e a acomodação. De acordo com Piaget:

Toda necessidade tende: $1^{\circ}$, a incorporar as coisas e pessoas à atividade própria do sujeito, ou seja, assimilar "o mundo exterior às estruturas já construídas, e $2^{\circ}$, a reajustar estas últimas em função das transformações ocorridas, ou seja, acomodá-las aos objetos externos (Piaget, 1964, p. 15).

Na assimilação, o sujeito age sobre o objeto de estudo com o intuito de entendê-lo por meio de referenciais cognitivos já possuídos. Ainda que esses referenciais, denominados por Piaget de esquemas cognitivos, sejam insuficientes para dominar o objeto como um todo, o aprendiz procura desvendá-lo trazendo-o para dentro de seus esquemas cognitivos. Nisso consiste o processo de assimilação. O processo subseqüente denomina-se acomodação. Nesse, ocorrem modificações nos esquemas cognitivos do aprendiz, desencadeadas em função do exercício assimilador. Assume-se, para tanto, que o objeto exerce pressão perturbadora sobre o sujeito, contribuindo para fornecer-lhe motivação e envolvimento pessoal, o que resulta em um impulso para a ação do sujeito sobre o objeto. Logo após, a atividade do sujeito, que se traduzirá em busca, pesquisa e ação sobre o objeto, será mais efetiva (Cunha, 2003).

Talvez o maior problema quanto a esta interação entre sujeito e objeto recai no fato de que, por si só, o aluno dificilmente se motivará de forma a superar o desnível existente entre ele e o conteúdo escolar. Caso não haja vínculos desafiadores entre o indivíduo e a matéria de ensino, vínculos os quais ativem a percepção do desnível entre o aprendiz e o conteúdo escolar, o educando não se motivará para estudar aquilo (Cunha, 2003). Não havendo motivação, o aluno não se posiciona ativamente diante da matéria. $O$ mesmo acontece quando o professor privilegia a passividade de seus alunos. Sem vontade e iniciativa não há conhecimento. 
Nesse sentido, a experimentação vem sendo defendida extensivamente como uma estratégia de ensino, a qual resulta em motivação nos alunos. Entretanto, há de se tomar devidas precauções quanto a esse discurso de modo a não provocar deturpações referentes às verdadeiras características e possibilidades da experimentação científica. Galiazzi et al. (2001) mapearam algumas importantes características da experimentação apontadas por estudantes de Química. Dentre elas se pode destacar: (i) um contexto mais amplo do que o escolar, (ii) necessidade de superar apenas uma teorização a partir da prática, (iii) importância do diálogo escrito e oral para a construção e validação de argumentos e explicitação do conhecimento, (iv) confrontar os resultados inesperados com os argumentos dados para justificar os resultados observados.

Dentro dessa perspectiva, o presente estudo objetivou uma atividade de intervenção direta em sala de aula para desenvolver conceitos científicos relacionados à pressão. As duas questões norteadoras do trabalho foram: Podem as atividades experimentais provocar perturbações nos alunos de modo a desencadear o processo assimilatório? A variação de uma atividade experimental auxiliará a acomodação dos conceitos científicos envolvidos?

\section{METODOLOGIA}

\subsection{O contexto da pesquisa}

O presente estudo foi fruto de um trabalho desenvolvido durante a disciplina de Prática de Ensino II do curso de Licenciatura em Química do Instituto de Química da UNESP de Araraquara, onde o estágio supervisionado em Química, obrigatório por lei, é conduzido na rede pública de ensino. Esse estudo refere-se à última etapa do projeto de estágio desenvolvido no período de março a dezembro de 2005, período no qual várias atividades de ensino são planejadas e postas em prática. A primeira etapa do estágio supervisionado foi a observação, na qual as aulas de Química foram assistidas pelos estagiários durante aproximadamente dois meses. Isso serviu, além de um contato com os alunos da escola, para se conhecer os conteúdos que vinham sendo abordados pelos 
respectivos professores responsáveis, auxiliando o preparo da atividade a ser desenvolvida.

Paralelamente, os licenciandos, em grupos de 4 a 5 integrantes, foram desenvolvendo planos de ensino que acompanharam o conteúdo abordado pelo professor em sala de aula. Os grupos dividiram-se de forma a atender as três séries do ensino médio. O planejamento das atividades de cada grupo foi discutido semanalmente com todos os estagiários, com a supervisora do estágio e com os professores de Química e/ou Física. Após o planejamento, cuja duração foi cerca de três meses, as atividades foram desenvolvidas com todos os alunos da escola. Cada grupo ficou responsável por uma ou duas salas. Na etapa seguinte, modificou-se o número de integrantes por grupo, agora de dois alunos, ocorrendo uma alternância na série com a qual se trabalhou, isto é, estagiários que desenvolveram atividades para o primeiro ano agora foram responsáveis pelo segundo ano e assim sucessivamente. Durante a última etapa do estágio, na qual se insere o presente trabalho, o planejamento foi feito individualmente, apenas com o auxílio da supervisora.

A investigação foi realizada junto a 33 alunos do segundo ano do Ensino Médio em uma escola da rede estadual localizada na cidade de Araraquara-SP. Optou-se por uma abordagem envolvendo atividades experimentais, as quais serão discutidas posteriormente. A coleta dos dados foi realizada por meio de questionários e fichas de observações experimentais preenchidas pelos alunos bem como anotações de campo. Nas fichas de observação, os alunos foram instruídos a observar atentamente e anotar, antes da realização de cada experimento, os materiais, as condições do sistema, o procedimento experimental e os resultados. Nos questionários, os alunos interpretaram situaçõesproblema e responderam questões abertas relacionadas aos experimentos. Um modelo da ficha de observação e dos questionários utilizados na pesquisa se encontra em anexo.

\subsection{A proposta de atividade em sala de aula}

O módulo de ensino planejado teve por objetivo um tratamento macroscópico dos conceitos de pressão e diferença de pressão com uma posterior abordagem microscópica. 
O planejamento foi conduzido no sentido de estabelecer níveis de conhecimento que fossem gradativamente superados a partir das atividades e intervenções, isto é, admite-se que o conhecimento adquirido sofre sucessivas modificações partindo de um estado inicial e chegando a outro, que nunca é definitivo. Por isso recorreu-se à epistemologia de Piaget, que entende a aprendizagem como um processo no qual, a partir de um desequilíbrio, o aprendiz chega ao estado de maior conhecimento, o qual sempre será o estágio inicial de um processo de equilibração subseqüente. Por isso as atividades experimentais são uma complementar à outra.

Os conceitos foram abordados de forma qualitativa e geral, evitando a apresentação de equações matemáticas e resolução de problemas numéricos. A atividade foi dividida em duas partes, sendo cada etapa realizada em aulas de 100 minutos. O primeiro momento compreendeu a realização de um simples experimento para demonstrar a diferença de pressão. Colocou-se em uma garrafa plástica de $2 \mathrm{~L}$ cerca de $200 \mathrm{~mL}$ de água quente (em torno de $60{ }^{\circ} \mathrm{C}$ ). Em seguida a garrafa foi esvaziada, teve sua boca fechada com a tampa e resfriada em água a temperatura ambiente. Quase instantaneamente a garrafa é comprimida devido à diferença de pressão entre seu interior e o ambiente. Em seguida repetiu-se o mesmo procedimento, porém a garrafa permaneceu aberta durante o experimento.

Foi pedido aos alunos que anotassem suas observações e explicações sobre o fenômeno observado. Nesse momento, foram levantadas as idéias dos estudantes acerca de gases, de como se comportam com a mudança de temperatura, da composição do ar atmosférico e da pressão atmosférica. Após os alunos fazerem suas próprias anotações, foi pedido a eles que descrevessem os principais aspectos do experimento realizado e que explicassem o porquê do esvaziamento de um pneu furado. O professor/estagiário então anotou na lousa as observações dos alunos. Em seguida iniciou-se a discussão sobre essas observações. Os alunos foram então levantando explicações sobre os fatos observados, também anotados na lousa pelo professor/estagiário. Após essa etapa e já na segunda aula, os alunos responderam a um questionário no qual explicaram novamente o esvaziamento de um pneu quando esse fura e justificaram a compressão da garrafa.

Na segunda etapa, utilizou-se também um experimento relacionado à diferença de pressão (Francisco Jr. e Dochi, 2006). Aqui os alunos trabalharam em grupos de quatro 
ou cinco alunos, discutindo suas observações e anotações aos pares. $\mathrm{O}$ professor/estagiário não centralizou sua discussão trabalhando separadamente em cada um dos grupos. Ao fim da atividade os alunos responderam a um outro questionário (questões em anexo) referente ao segundo experimento.

\section{RESULTADOS E DISCUSSÃO}

\subsection{Primeira atividade: A compressão da garrafa}

A elaboração de atividades experimentais privilegia estratégias não muito comuns em escolas públicas, permitindo, por conseguinte, trabalhar com os alunos atividades não habituais como observação, anotações, elaboração de hipóteses, argumentação, dentre outras. Nesse contexto, os experimentos propostos tiveram por objetivo mostrar aos alunos o caráter empírico da ciência, a importância das observações experimentais, a atenção na coleta dos dados, as explicações iniciais, a discussão, enfim, os princípios da construção de um conhecimento científico.

Assim, no início, os alunos apenas se ativeram a anotações escritas para em seguida tentarem explicitar ou prever os fenômenos observados. Dessa forma, valorizaram-se as anotações, as observações e principalmente os registros escritos dos alunos. Escrever nas aulas de ciências requer uma posição reflexiva, o que estimula os estudantes a refinar seus pensamentos e aumenta o entendimento do tema estudado (Carvalho e Oliveira, 2005).

A análise das anotações iniciais dos alunos mostrou que grande parte (20 alunos) atribuiu a compressão da garrafa ao choque térmico:

- "A água fria fez a garrafa entortar pelo choque térmico."

- "Na garrafa foi colocada água quente e depois retirou e colocou água fria causando um choque térmico fazendo com que a garrafa ficasse amassada." 
Mesmo que essas idéias e suas relações ainda sejam insuficientes e primitivas, tal visão refere-se a um primeiro nível de elaboração conceitual dos estudantes, no qual os estudantes buscam dar sentido à realidade com base em suas observações. De acordo com Aguiar Jr. e Saraiva (1999):

Todos nós, adultos escolarizados, temos essa reação cognitiva quando nos deparamos com objetos de conhecimento com os quais temos pouca ou nenhuma experiência. Nesse caso, procuramos estabelecer qualidades observáveis que permitam conferir sentido à experiência (Aguiar Jr. e Saraiva, p. 5, 1999).

Ao mesmo tempo, tais resultados mostram que os estudantes não possuíam um conhecimento prévio consolidado, mas sim lacunas conceituais, o que fez os estudantes explicarem a deformação da garrafa baseados apenas em suas observações. Como destaca Mortimer (1995), estratégias baseadas na mudança conceitual falham justamente nesse ponto, ao ignorar que, muitas vezes, o que falta aos alunos são conhecimentos suficientes para explicitar alguns fenômenos ou generalizar as explicações a outros fenômenos.

Os demais alunos não explicitaram o motivo da compressão da garrafa. No que concerne às observações experimentais anotadas pelos alunos, as duas principais foram referentes ao uso da água quente e a necessidade de se manter a garrafa fechada. Essas observações foram então debatidas em sala de aula para construção e fortalecimento dos argumentos.

Essa atividade mostrou-se surpreendente, uma vez que a grande maioria dos alunos participou ativamente, levantando questões, opiniões e argumentos. Ao final, chegou-se ao denominador comum de que o ar externo à garrafa influenciou o seu colapso, por isso, quando o experimento foi realizado com a garrafa aberta, nada foi observado, como sublinham alguns escritos dos estudantes.

- “Com a tampa aberta não é possível amassala porque o ar esta proporcional fazendo com que as pressões do ambiente esteje igual a da garrafa." 
- "Sem tampa não faz nada pois no primeiro caso a garrafa prendia o ar quente na garrafa."

Outra importante conclusão dos alunos foi a respeito da diferença de temperatura entre o interior e o exterior da garrafa. Os estudantes mostraram-se atentos à temperatura da água, pedindo que o experimento fosse repetido com água à temperatura ambiente. Isso mostra a capacidade de observação e curiosidade, elementos que podem tornar-se motivadores na aprendizagem, fato que, aí sim, justifica a experimentação como atividade motivadora. Para tanto, é imprescindível que o desequilíbrio entre o nível de conhecimento dos estudantes e o nível necessário para interpretar os fenômenos não seja grande em demasia. Isso dificultaria a ascensão dos estudantes de um nível ao outro, provocando o desinteresse.

O mais importante na etapa inicial de elaboração dos conceitos é a capacidade de conferir instrumentos que possam engendrar a compreensão dos fenômenos (Aguiar Jr. e Saraiva, 1999; Aguiar Jr., 2004). Nessa etapa constataram-se elementos que descrevem o observável, como o fato da garrafa estar aberta e por isso não reter o ar quente. Dado que os estudantes possuíam conhecimentos acerca do aumento da vibração molecular com o aumento de temperatura, conseguiram relacionar tal idéia à deformação da garrafa a partir da observação experimental.

No que concerne à explicação dos alunos sobre o esvaziamento de um pneu quando furado, 26 alunos responderam "porque o ar vaza", não explicitando com maiores detalhes o vazamento do ar, dificultando de certo modo a análise. Por outro lado, como já discutido, tais resultados evidenciam a presença de lacunas conceituais, as quais podem nortear o planejamento de ensino no sentido de supri-las. De acordo com Mortimer (1995):

(...) as lacunas são tão importantes quanto os conflitos. São poucos os autores que se referem às lacunas como um tipo de perturbação. Várias estratégias baseadas no conflito cognitivo parecem não reconhecer que, muitas vezes, no processo de construção de uma idéia nova, a falta de informações para interpretar os resultados de um experimento é obstáculo maior (...) (Mortimer, p. 4, 1995). 
Já a análise dos questionários respondidos após o desenvolvimento e discussão do experimento mostrou que os alunos passaram a incorporar os termos pressão e diferença de pressão em seus textos, como pode ser observado abaixo, para a explicação do esvaziamento do pneu e da compressão da garrafa plástica:

- "O ar vaza porque a pressão do ambiente é maior e empurra o ar para fora.”

- “Na garrafa há moléculas, e essas moléculas fazem pressão na garrafa e quando colocada na água fria a temperatura diminui e as moléculas começam a agitar menos e com a pressão do ambiente (atmosférica) que é mais forte do que a que está dentro da garrafa ela amassa."

Enquanto no nível inicial de aprendizagem os estudantes se valiam apenas de elementos observáveis, aqui eles se apóiam nas idéias anteriores (a visualização da compressão da garrafa) para engendrar explicações sobre o fenômeno, "a atenção voltase para as relações entre os estados inicial e final e para os modos como, partindo de um estado, chegamos a outro" (Aguiar Jr. e Saraiva, p. 6, 1999). Portanto, pode-se verificar uma evolução nas construções que passaram a incorporar termos científicos. Além disso, para explicar a compressão da garrafa, boa parte dos alunos (16 alunos) utilizou desenhos similares aos apresentados nas Figuras 1, 2 e 3.

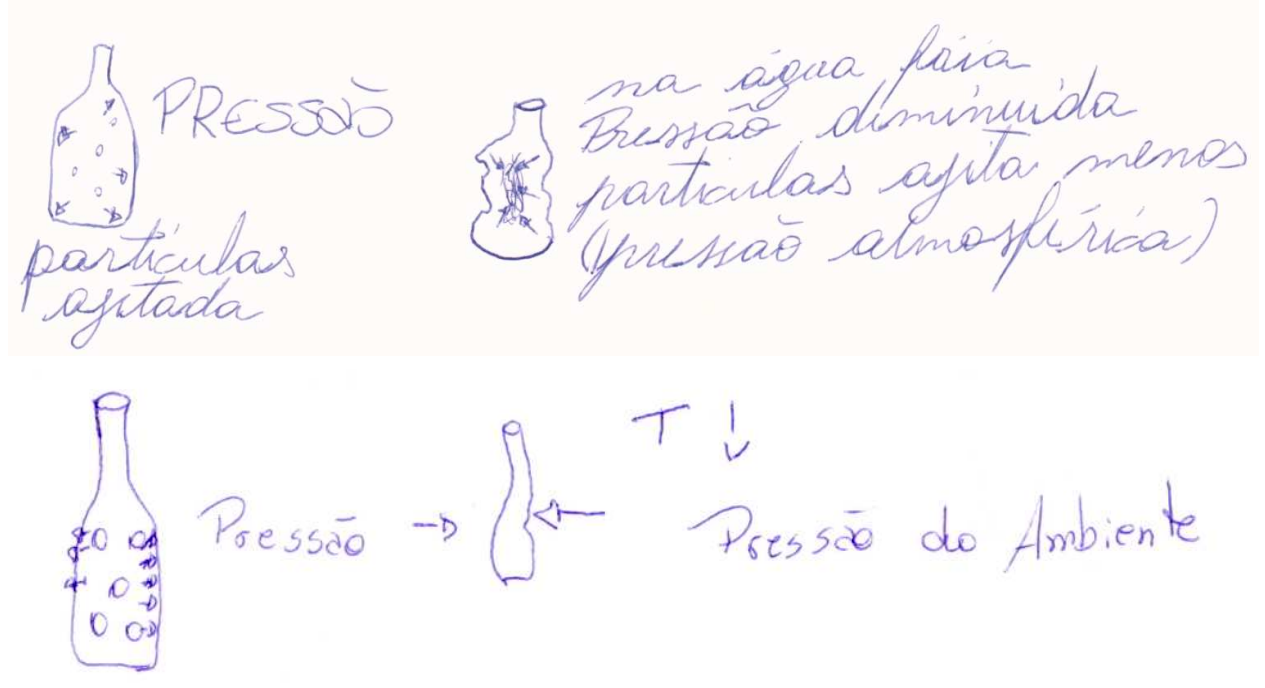


Figura 1. Desenhos apresentados por alunos para explicar a compressão da garrafa plástica.

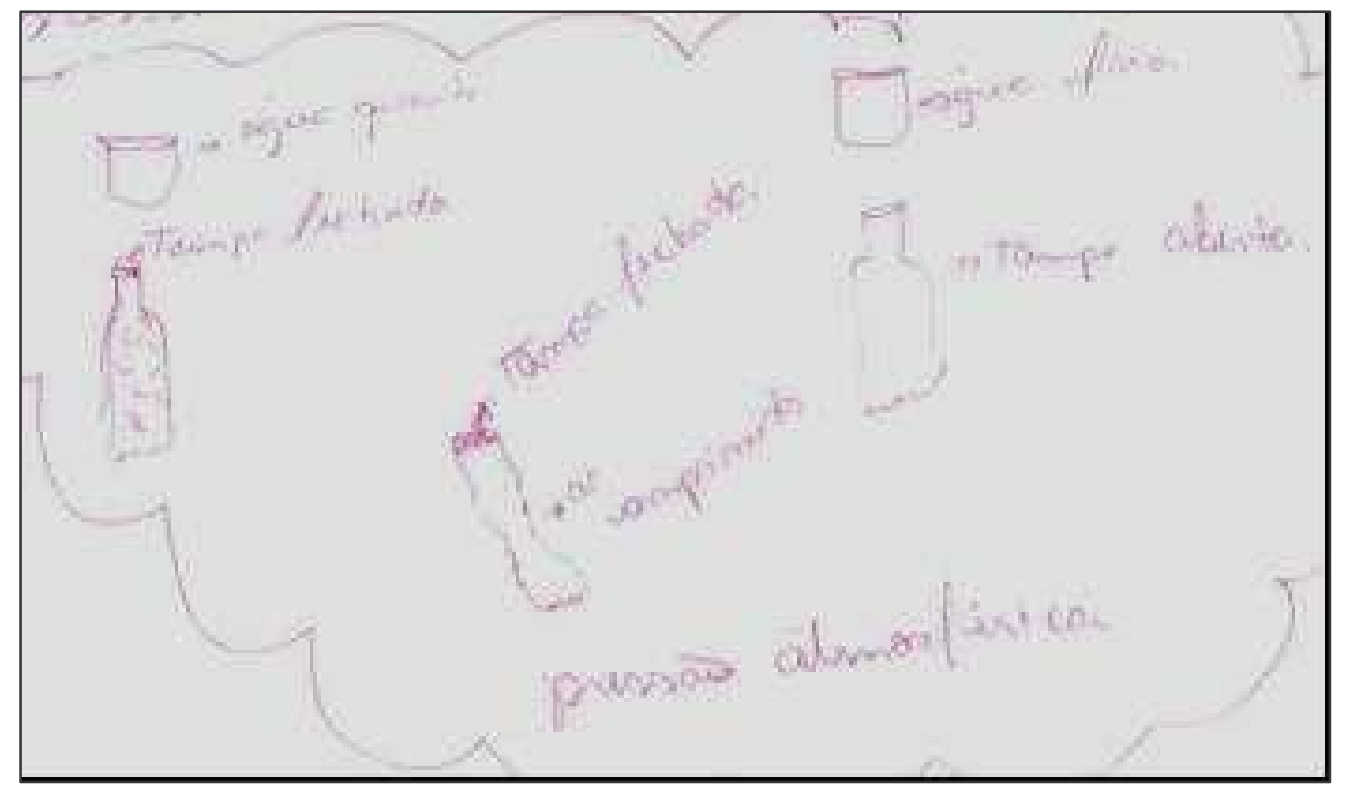

Figura 2. Desenho relacionando a questão do fechamento da garrafa com a tampa e o seu colapso.

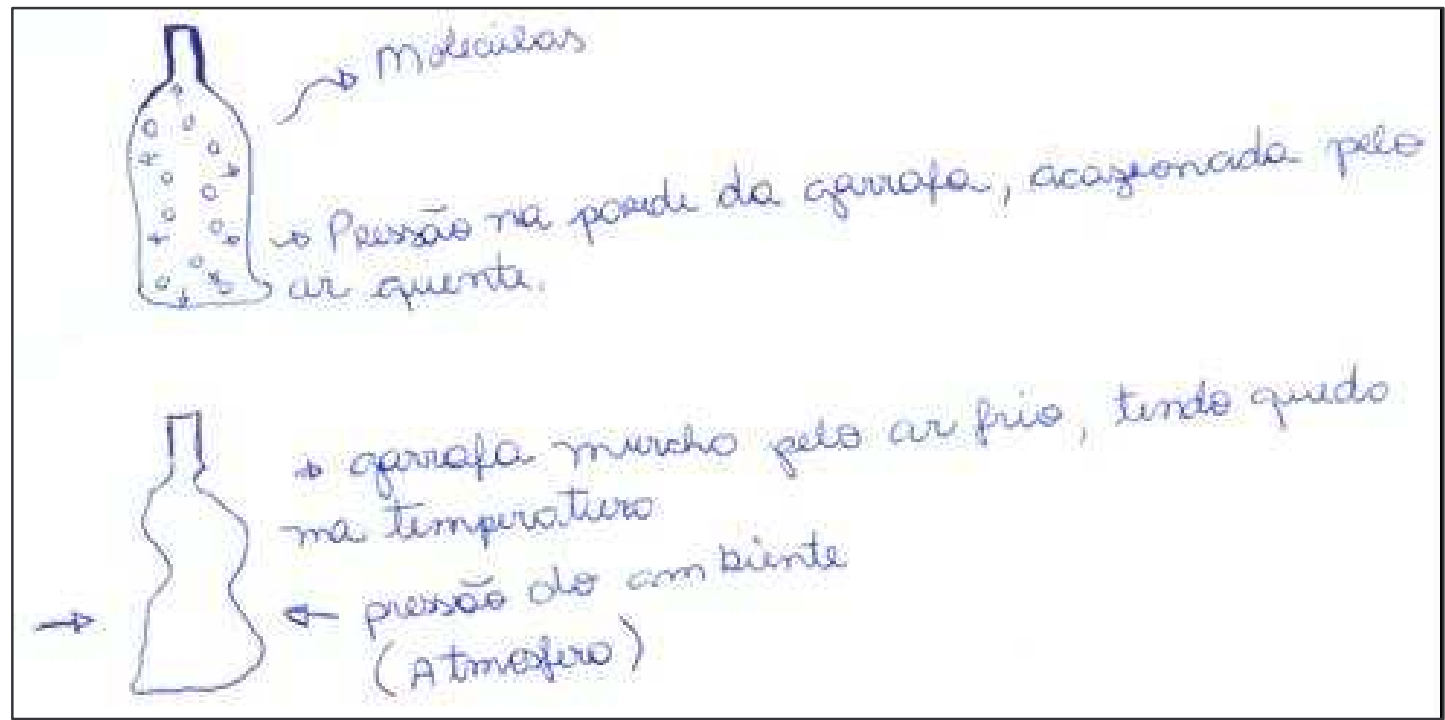

Figura 3. Desenho mostrando a importância das moléculas gasosas na pressão. 
Os desenhos apresentados pelos estudantes mostram que eles conseguiram adquirir a idéia de modelo de gases, levando em conta, também, a agitação constante das moléculas. Isso se torna muito importante, uma vez que a Química trata de idéias bastante abstratas e, portanto, requer que os estudantes tenham constantemente modelos representacionais em suas cabeças. Isso demonstra que, após a discussão, os alunos se ativeram mais às transformações e suas explicações, do que simplesmente às observações, como visto anteriormente. Tal fato já retrata um processo de acomodação das novas informações, como a diferença de pressão devido à agitação molecular.

O desenvolvimento dessa primeira atividade experimental focou, sobretudo, despertar nos alunos capacidades tais como observação, coleta de dados etc. Assim, no início os alunos apenas se ativeram a anotações escritas para, em seguida, tentarem explicitar ou prever os fenômenos observados.

Entende-se que o questionamento é o primeiro movimento da atividade experimental (Gonçalves e Galiazzi, 2004), e fazer uso de informações escritas é um importante recurso para a problematização do conhecimento. A previsão ou justificativa de um fenômeno revela importantes conhecimentos dos alunos sobre o tema.

Esse conhecimento explicitado pelo aprendiz permite que o professor possa mapear alguns dos conhecimentos do grupo sobre o tema estudado na atividade experimental. É importante salientar que a explicitação do conhecimento não se restringe somente ao inicio da atividade experimental, ocorrendo nos diferentes momentos da sala de aula, o que exige atenção permanente do professor. As previsões, além de serem utilizadas no início de uma atividade experimental, também podem auxiliar a perceber as aprendizagens dos alunos. Nesse caso o professor pode procurar variações da mesma atividade experimental que possibilitem problematizar o conhecimento dos alunos sobre o tema (Gonçalves e Galiazzi, 2004, p. 247).

\subsection{A segunda atividade: A entrada de água na seringa}


A partir das idéias de Gonçalves e Galiazzi (2004) foi realizado um outro experimento relacionado também à diferença de pressão. Nesse, os alunos tiveram de prever e explicar a entrada de água na seringa. Aqui, além de se analisar o processo de equilibração e a capacidade de generalização dos estudantes em relação ao conceito de diferença de pressão, a atividade buscou desencadear novas perturbações. Em relação à explicação do fenômeno ocorrido neste segundo experimento (entrada de água na seringa), os alunos mantiveram no seu discurso termos científicos, como pode ser observado em algumas das respostas obtidas:

- "A pressão atmosférica é maior então empurra a água para dentro da seringa."

- "Observamos que a seringa começa a se encher de água, isso porque a pressão dentro da seringa é menor do que a de fora."

- "A pressão da seringa diminui e começa a ocorrer as mudanças como por exemplo entrar água na seringa."

- "A pressão da seringa se tornou menor que a pressão de fora. As pressões tendem a se igualar e como a pressão do ambiente externo é maior empurrou a água pra dentro da seringa."

Tais resultados sublinham uma etapa na qual o nível de conhecimento é mais abrangente e os estudantes buscam prever e generalizar as explicações, de modo que essas atendam à realidade. Nessa etapa a compreensão do fenômeno como um todo se torna mais articulada. Segundo Aguiar Jr. e Saraiva (1999) "as formas de entendimento mais primitivas são superadas por outras que aumentam seus poderes de assimilação $e$ modificam os instrumentos que utiliza para dar sentido à realidade” (p. 7).

Outro aspecto interessante foi a capacidade de observação de detalhes que alguns alunos mostraram, o que evidencia um caráter investigativo e de curiosidade. 
- "Colocou bombril molhado no vinagre dentro da seringa e mergulhou-o no copo com água e assim a seringa começou a encher de água e o bombril ficou cheirando ferrugem."

Apenas um aluno levantou questões referentes ao porque da oxidação da esponja de aço.

- "O vinagre começa a oxidar o bombril. O vinagre oxida o ferro do bombril por causa do ácido.”

O professor/estagiário não direcionou a discussão para o entendimento das causas de oxidação da esponja de aço, pois esse não era o objetivo do módulo de ensino. Contudo, especificamente com esse aluno, foi discutida a causa da oxidação da esponja, uma vez que ele levantou a questão em suas observações. Similarmente ao experimento da compressão da garrafa, os alunos construíram desenhos para entenderem melhor o que aconteceu (Figuras 4 e 5). Isso é de grande relevância, uma vez que requer dos alunos muita atenção durante as observações experimentais, ao mesmo tempo em que possibilita aos alunos uma rica expressão lingüística.

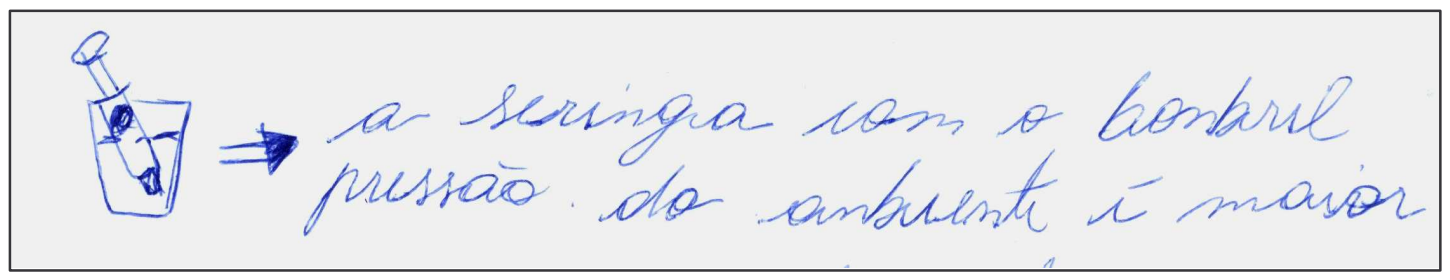

Figura 4. Desenho apresentado por um dos alunos para ilustrar a entrada de água na seringa. 


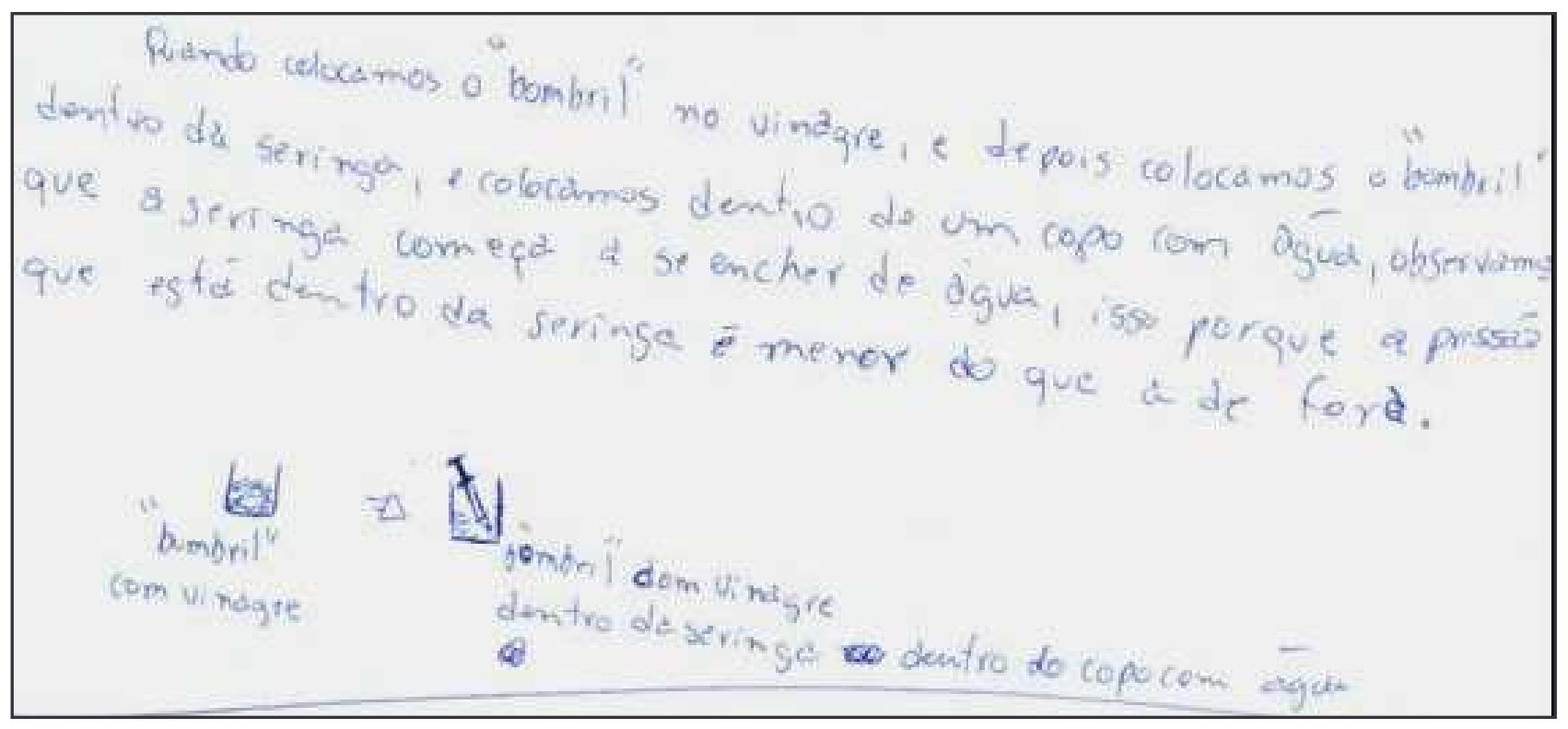

Figura 5. Explicação da entrada da água na seringa acompanhada de ilustração.

Tomando-se como paralelo a teoria piagetiana, variações de uma mesma atividade experimental servem como etapa adaptativa para os aprendizes modificarem seus esquemas cognitivos, isto é, funcionam como etapas pré ou até mesmo assimiladoras. Essas atividades seriam como "andaimes" para o aluno superar o desnível diante do objeto. Ainda que possa ocorrer assimilação sem acomodação (quando a tarefa é idêntica ou compreende fatos e aspectos já conhecidos) a recíproca não é verdadeira. Toda nova informação carreia uma perturbação gerada por conflitos ou lacunas, caso contrário não há construção do conhecimento. No tocante à primeira parte do modelo de ensino, a perturbação foi gerada por uma lacuna relacionada ao conceito de diferença de pressão. “A lacuna passa a uma perturbação quando se trata de ausência de um objeto ou das condições de uma situação que seriam necessárias para realizar uma ação, ou, ainda, da carência de um conhecimento indispensável para resolver um problema" (Piaget citado por Mortimer, 2000, p. 42).

Uma vez que as lacunas estão relacionadas a esquemas de assimilação já ativados, na segunda etapa os alunos não encontraram problemas para explicitar o conceito de diferença de pressão. A grande maioria (25 alunos) mencionou que com a seringa aberta a água não subiria, pois não existe diferença de pressão. Em suma, a lacuna existente no primeiro momento (primeiro experimento) provocou perturbações que tiveram de ser 
absorvidas pelo sistema cognitivo dos alunos, caracterizando o processo de assimilaçãoacomodação, o qual os levou a atingir um novo estado de equilíbrio diferente e superior ao anterior, uma vez que incorporaram a perturbação como algo dedutível e previsível.

Observam-se, outrossim, três etapas ou níveis de conhecimento. Um primeiro no qual estão presentes apenas elementos observáveis, um segundo em que aparecem elementos pelos quais os estudantes buscam compreender as transformações do sistema e, por último, uma etapa quando a busca é por uma generalização das idéias. Nessa última etapa, os alunos utilizaram as idéias de diferença de pressão na compressão da garrafa plástica para explicar a entrada de água na seringa. Essas configuram as tríades dialéticas de Piaget, denominadas de intra, inter e trans (Aguiar Jr. e Saraiva, 1999; Aguiar Jr., 2004).

Porém, apesar de conseguirem explicar a entrada de água na seringa pela diferença de pressão, outra lacuna, agora relacionada ao motivo da diminuição da pressão no interior da seringa, desencadeou novas perturbações. No caso dessas lacunas são necessários outros reforços e/ou novos conhecimentos. Observa-se, nesse caso de perturbações ocorridas por lacunas, que a estratégia não é criar conflitos nos alunos, mas sim criar situações motivadoras que os possibilitem a interagir com o objeto (Mortimer, 2000).

Cabe aqui ressaltar que o nível de conhecimento a que os estudantes chegam nunca é definitivo. Os alunos, sempre que desafiados, deverão alterar seus esquemas cognitivos para assimilarem e acomodarem mais conhecimentos e outros desequilíbrios. Tal movimento se configura como um espiral (Aguiar Jr. e Saraiva, 1999), no qual o último patamar no processo de acomodação de um determinado conceito torna-se o primeiro do processo subseqüiente.

\section{CONCLUSÕES}

Obviamente este trabalho tratou apenas de questões qualitativas no tocante aos conceitos de pressão e diferença de pressão. Os resultados apresentados poderiam ser diferentes caso aspectos quantitativos tivessem sido estudados, uma vez que esses 
envolveriam outros esquemas cognitivos por parte dos alunos, como o equacionamento matemático etc. Entretanto, a proposta metodológica de ensino desenvolvida mostrou ser uma estratégia motivadora e capaz de desencadear perturbações e auxiliar o desenvolvimento do processo de assimilação dos conceitos aqui tratados. Outrossim, a atividades experimentais complementares mostraram ser importantes para uma melhor compreensão dos conceitos pelos alunos, uma vez que uma serve de subsídio à outra.

As atividades experimentais complementares auxiliam os estudantes na apreensão dos fenômenos, pois, além de constituírem-se como potencialmente motivadoras, abarcam em si, etapas ou níveis de conhecimento requerentes ao entendimento do fenômeno como um todo. Todavia, são necessários planejamento e análise cuidadosos, uma vez que o professor deve perceber quando a estratégia requer um salto muito grande de conhecimento, o que dificulta a aprendizagem.

Nesse tipo de atividade, é fundamental também que os professores se detenham aos registros escritos produzidos nas aulas, especialmente em aulas cuja investigação é a base metodológica de ensino. Isso permite perceber o nível de entendimento dos alunos por meio de uma rica expressão lingüística e gráfica.

\section{REFERÊNCIAS}

AGUIAR JR., O. Um modelo piagetiano de ensino como ferramenta para o planejamento do ensino e a avaliação da aprendizagem. Ensaio: Pesquisa em educação em ciências, v. 6, n. 2, 2004. Disponível em http://www.fae.ufmg.br:8080/ensaio/v6_n2/aguiar.pdf.

AGUIAR JR., O.; SARAIVA, J. F. Modelo de ensino para mudanças cognitivas: Fundamentação e diretrizes de pesquisa. Ensaio: Pesquisa em educação em ciências, v. 1, n. 1, 1999. Disponível em http://www.fae.ufmg.br:8080/ensaio/v1_n1/1_3.pdf.

CARVAlho, A. M. P.; OliveirA, C. M. A. Escrevendo em Aulas de Ciências. In: CONGRESO INTERNACIONAL SOBRE INVESTIGACIÓN EN LA DIDÁCTICA DE 
LAS CIENCIAS: Educación científica para la ciudadanía, 7., Granada. 2005. Atas... Granada, 2005. p. 1-6.

CUNHA, M. V. Psicologia da Educação. $3^{\text {a }}$ ed. Rio de Janeiro: DP\&A, 2003.

FRANCISCO JR., W. E.; DOCHI, R. S. Um experimento simples envolvendo óxidoredução e diferença de pressão com materiais do dia-a-dia. Química Nova na Escola, v. 23, p.49-51, 2006.

GALIAZZI, M. C.; ROCHA, J. M. B.; SCHMITZ, L. C.; SOUZA, M. L.; GIESTA, S.; GONÇALVES, F. P. Objetivo das atividades experimentais no ensino médio: a pesquisa coletiva como modo de formação de professores. Ciência e Educação, v. 7, p. 249-263, 2001.

GONÇALVES, F. P.; GALIAZZI, M. C. A natureza das atividades experimentais no ensino de Ciências: um programa de pesquisa educativa nos cursos de Licenciatura. In: Moraes, R.; Mancuso, R. Educação em Ciências: produção de currículos e formação de professores. Ijuí: Unijuí, 2004. p. 237-252.

MORTIMER, E. F. Construtivismo e mudança conceitual em sala de aula: Para onde vamos? Investigações em Ensino de Ciências, v. 1, n. 1, 1995. Disponível em http://www.if.ufrgs.br/public/ensino/revista.htm.

MORTIMER, E. F. Linguagem e Formação de Conceitos no Ensino de Ciências. Belo Horizonte: UFMG, 2000.

PIAGET, J. Seis estudos de psicologia. Rio de Janeiro: Forense Universitária, 1964. 


\section{ANEXO \\ Modelo da ficha de observação utilizada pelos estudantes}

Materiais (anote aqui tudo que será utilizado para a realização do experimento):

Condições (descreva informações que você consegue perceber, tais como a temperatura da água, o tipo de garrafa, seu formato, etc):

Procedimento experimental (descreva passo a passo o que é realizado no experimento):

Anote ou desenhe com detalhes suas observações (compare as condições que você anotou antes do experimento ser realizado e o que aconteceu após os procedimentos experimentais):

\section{Questionário (primeiro experimento)}

1. Quando um pneu é furado, observamos que ele sofre um esvaziamento. Você consegue explicar porque isso acontece?

2. Explique porque a garrafa sofreu uma deformação após a adição e retirada da água quente e após o fechamento da garrafa com a tampa e resfriamento.

3. Porque não se observou a deformação da garrafa quando esta permaneceu aberta?

\section{Questionário (segundo experimento)}

1. Explique porque a água sobe do copo para a seringa.

2. Caso mantivéssemos a seringa aberta, será que a água também entraria na seringa? 